\title{
O TRADUTOR COMO COADJUVANTE NA PRODUÇÃO AUTOMÁTICA DE TRADUÇÕES
}

Érika Nogueira de Andrade Stupiello é professora da Unesp, Campus de São José do Rio Preto. Doutora em Estudos Linguísticos e tradutora pública, desenvolve pesquisas sobre as relações entre a prática de tradução e a adoção de novas tecnologias pelo tradutor. E-mail: erika@ibilce.unesp.br

\section{Resumo}

Este trabalho apresenta uma análise sobre como a tradução automática tem modificado a maneira como a tradução é concebida e praticada na era da informação. Partindo de uma breve revisão sobre as concepções iniciais dos programas de tradução automática, discuto as mudanças promovidas nas últimas décadas nesses sistemas para unir o processamento mecânico ao trabalho acessório do tradutor.

\begin{abstract}
This paper analyzes how machine translation has changed the way translation is conceived and practiced in the information age. From a brief review of the early designs of machine translation programs, I discuss the changes implemented in the past decades in these systems to combine mechanical processing and the accessory work by the translator.
\end{abstract}

A tradução humana e a tradução automática são como 'animigas,' ... Elas convivem bem próximas, mas com muita tensão...

PRI's the World, 20 ago. 2013, tradução nossa

Entre as diversas tecnologias disponíveis ao tradutor, os sistemas de tradução por máquina parecem constituir uma das mais controversas ferramentas justamente por representarem a ameaça de, um dia, serem capazes de dispensar o trabalho humano. Desde a primeira tentativa de automatização de tradução, representada por um sistema desenvolvido pela IBM para traduzir frases do russo para o inglês no início da Guerra Fria, 
aos atuais programas mundialmente comercializados, muito se investiu em pesquisas com o objetivo de alcançar um sistema que igualasse a capacidade humana de verter textos entre línguas diferentes.

De acordo com Martins (2003), o entusiasmo inicial com os primeiros sistemas acirrou-se pela convicção de que uma língua estrangeira seria apenas um código com símbolos desconhecidos e, por esse motivo, sua tradução seria passível de transcodificação, materializada em uma relação "biunívoca" entre símbolo e referente. Essa visão de língua que por muito tempo sustentou a pretensão das pesquisas em tradução automática fundamentava-se na possibilidade de alcançar sistemas completamente independentes e capazes de produzir traduções íntegras, que dispensassem revisão e que fossem concluídas em tempo muito menor do que aquele requisitado pelo tradutor humano.

Entretanto, sistemas desenvolvidos nesses moldes frequentemente apresentavam resultados limitados, uma vez que os recursos linguísticos e computacionais empregados eram incapazes de representar automaticamente as operações mentais realizadas pelo tradutor humano. Além disso, conforme explica Curado (2000), grande parte dos projetos de tradução automática enfrentava problemas já em sua concepção por serem desenvolvidos com base na possibilidade de uma sentença produzir uma única interpretação, ignorando fatores contextuais de natureza extralinguística que, em sua maioria, não seriam passíveis de representação por algoritmos e nem de transferência para a máquina.

A busca por um sistema que pudesse igualar ou substituir o trabalho humano foi colocada de lado na década de 80 , período em que se descartou a possibilidade de uma tradução totalmente automática e que abrangesse todos os tipos de textos, e se passou a considerar a viabilidade de automatização de parte do processo tradutório, o que reduziria a complexidade e o tempo de execução da tradução de textos específicos que contassem com uma forma padronizada de utilização da língua. Pesquisadores da área de Linguística Computacional, que concentra as pesquisas em tradução automática, passaram a buscar alternativas para vencer as restrições de desempenho da máquina. Um dos caminhos tomados pelas pesquisas em automatização culminou no desenvolvimento de sistemas capazes de combinar esforço humano e mecânico de forma a reduzir os custos e o tempo do trabalho de tradução. 
O desenvolvimento de um sistema que reunisse o trabalho mecânico e humano foi advogado por Kay (1997), em um artigo considerado seminal à discussão sobre a aplicação da automatização em tradução, denominado The proper place of men and machines in language translation [O lugar adequado dos homens e das máquinas em tradução]. Nele, Kay vê com descrença os rumos na época tomados pelas pesquisas em automatização em sua busca por eliminar a intervenção humana, relegando ao tradutor a função de pós-edição da produção automática. Para o pesquisador, seria mais produtivo almejar o desenvolvimento de um sistema que pudesse reunir trabalho mecânico e humano pela aplicação de recursos informatizados com a finalidade exclusiva de ampliar a produtividade humana. Conforme defende Kay (1997, p.11), "a eficiência de um sistema de tradução, como a de qualquer outro, deve ser avaliada em todos os seus componentes: humanos e mecânicos".

Apesar das críticas e dos fracassos iniciais, além do fato de estar ainda condicionada à produção de um trabalho incompleto, a tradução automática tem lugar na vida moderna globalizada. Na medida em que a quantidade de textos e documentos a serem traduzidos aumenta exponencialmente, o tempo concedido para execução dessas traduções tem se tornado cada vez menor e, por isso, a automatização tende a se tornar atraente. Além disso, a adoção de sistemas de tradução automática tem-se mostrado economicamente viável para alguns usuários, uma vez que se imagina possível uma produção de qualidade que exija esforço humano somente em parte do processo de tradução.

Este trabalho aborda as inevitáveis mudanças que os sistemas de tradução automática promovem no desempenho do tradutor, bem como na maneira como suas habilidades são atualmente concebidas por contratantes de seu trabalho. Conforme discuto, a contratação do tradutor na contemporaneidade não mais se restringe a conhecimentos linguísticos e extralinguísticos na leitura e reconstrução do sentido na língua da tradução, mas envolve igualmente o requisito de domínio do manuseio das novas tecnologias que têm lugar definitivo no processo de tradução.

\section{1)O reconhecimento da limitação da máquina e a mudança de estratégia de trabalho na era da informação}


Uma das formas de reduzir o tempo de elaboração de uma tradução e, ilusoriamente, eliminar os efeitos da intervenção humana na comunicação, seria pela instrumentalização do trabalho do tradutor. Ferramentas desenvolvidas com o intuito de aumentar o desempenho tradutório seriam eficazes ao reduzirem o tempo de contato do tradutor com o material a ser traduzido. Essa situação é particularmente reveladora no cenário em que a tradução é praticada na era da informação. A instantaneidade da transmissão eletrônica de informações ganha primazia sobre o tempo de elaboração e revisão do material textual que circula em meio eletrônico. A retomada das pesquisas e a recuperação dos investimentos em programas de tradução automática representa, no contexto contemporâneo, uma tentativa de atender à demanda criada pelo mercado eletrônico de produção de documentação instaurado na internet.

Anteriormente ao advento da rede mundial de computadores, a pretensão sustentada para as pesquisas em tradução automática fundamentava-se na possibilidade de alcançar sistemas completamente independentes e capazes de produzir traduções íntegras, que dispensassem revisão e que fossem concluídas em tempo muito menor do que aquele requisitado pelo tradutor humano. Na década de sessenta, constatou-se que os investimentos direcionados ao desenvolvimento de programas que produzissem uma tradução totalmente automática de alta qualidade (conhecidos pela sigla em inglês FAHQT: Fully Automatic High Quality Translation) não alcançavam resultados aproveitáveis, como ansiavam seus proponentes. Em um relatório ao Conselho Consultivo em Processamento Automático de Línguas (ALPAC) - encomendado pelo governo norte-americano que, naquela época, financiava grande parte das pesquisas - concluiu-se que os limitados resultados dos projetos então apresentados eram inexecutáveis e, portanto, recomendou-se a suspensão dos investimentos em pesquisas de programas totalmente automáticos.

O relatório ALPAC é considerado uma espécie de linha divisória entre um período de euforia em relação aos primeiros (e restritos) resultados de programas de tradução automática e a interrupção das pesquisas subsidiadas pelo governo dos Estados Unidos. As conclusões apresentadas por esse relatório redefiniram e redirecionaram as linhas de pesquisa em aplicação de automatização em tradução a partir da década de setenta, embora a maioria dos pesquisadores e patrocinadores dos projetos desenvolvidos a partir daquela época tenha persistido no ideal de acesso ao significado em língua estrangeira sem mediação humana. 
As pesquisas da era pós-ALPAC voltaram-se para projetos de sistemas automáticos que envolvessem assistência humana estritamente na pós-edição da produção traduzida, para a elaboração de modelos teóricos que pudessem contribuir ao aprimoramento dos métodos de automatização e para o desenvolvimento de ferramentas eletrônicas de tradução. Todos esses projetos partiam de uma suposta "tradução rudimentar" (rough translation) produzida de modo automático e carecendo exclusivamente de lapidação estilística pelo tradutor humano, conforme esclarece Hutchins (2001), um dos teóricos mais representativos do pensamento da área.

A ideia de que a automatização poderia conduzir a traduções estilisticamente imperfeitas, mas capazes de conferir acesso a um conteúdo em uma língua estrangeira depositado no texto de origem e nele mecanicamente decifrável, mostra-se prevalente na literatura e nas propostas de projetos de tradução automática nas últimas décadas. Como esclarece Hutchins (2007), textos traduzidos de maneira automática atenderiam à necessidade de informar o leitor sobre seu "conteúdo". Nesse cenário, o tradutor seria empregado especificamente para o trabalho de revisão ou "pós-edição" da produção da máquina. Conforme explica Hutchins,

[...] existem basicamente dois tipos de demanda. Há a necessidade tradicional de traduções de qualidade "publicável", particularmente a produção de documentação multilíngue para grandes empresas. Nesse caso a produção dos sistemas de tradução automática pode economizar tempo ao oferecer traduções rudimentares que são depois editadas para publicação - esse uso é denominado tradução automática auxiliada por humanos (HAMT). Por outro lado, frequentemente não é necessária uma versão "perfeitamente" exata, mas algo que possa ser produzido rapidamente (às vezes, imediatamente), que transmita a essência do original, embora gramaticalmente imperfeito, lexicalmente desajeitado e estilisticamente grosseiro. Essa produção é, em geral, denominada "tradução automática para assimilação", em contraste com a produção de traduções de qualidade publicável, conhecidas como "tradução automática para disseminação". (HUTCHINS, 2007, p.1, tradução nossa)

Observa-se, pelo relato de Hutchins, que em ambas as demandas por tradução que enumera, os sistemas automáticos atuam como realizadores efetivos do trabalho de tradução, seja acelerando a conversão de significados de textos estrangeiros para as línguas traduzidas com fins de publicação, seja oferecendo uma "versão" que, embora com reconhecidas restrições na forma, apresentaria "a essência do original". Somente em 
situações em que uma tradução fosse encaminhada para publicação, o tradutor atuaria como coadjuvante ao trabalho da máquina, restritamente na adequação da forma de apresentação de um significado já recuperado de sua origem.

No entanto, por outro ponto de vista, é possível afirmar que o olhar humano está sempre presente, em ambas as situações de aplicação de automatização. Na tradução para "assimilação", o sentido da produção automática só é conferido pela interpretação humana que constrói o significado, não obstante "gramaticalmente imperfeito, lexicalmente desajeitado e estilisticamente grosseiro". Na produção para disseminação, o trabalho humano (nesse caso específico, do tradutor) seria muito mais abrangente do que a pósedição da tradução automática. Sua atuação se estende à elaboração do sentido conferido à produção automática para a devida conciliação entre o mecânico e a elaboração textual.

A concepção contemporânea da função da tradução automática teria ganhado uma nova "roupagem", propositalmente mais aprazível aos críticos da automatização de outrora, porém ainda comprometida com os ideais primeiramente concebidos e perseguidos para a máquina. $\mathrm{O}$ anseio, por muito tempo gerado pelos projetos em tradução automática, da possibilidade de substituição do tradutor parece conceder lugar à imagem de que esses sistemas são capazes de atuar com maior eficácia como "ferramentas de produtividade" para o tradutor (Hutchins, 2007).

Levada às últimas consequências, essa aparente mudança de postura em relação aos sistemas de tradução automática revela transformações na produção e na recepção de textos assim traduzidos. Na produção de textos com fins de "disseminação", o reconhecido fracasso de se adaptar a máquina à expressividade das línguas tem promovido esforços no sentido de adequar e controlar a língua de origem para possibilitar a aplicação de processamento automático. Em textos destinados à "assimilação" de informações, a recepção de materiais traduzidos automaticamente também é influenciada na medida em que a expectativa com relação à produção da máquina restringe-se ao fornecimento das informações que estariam "contidas" no texto.

Seja em traduções para posterior publicação ou para conhecimento geral do texto, o trabalho do tradutor parece deslocar-se para uma posição coadjuvante na elaboração do texto traduzido, com atuação mais voltada à correção de falhas e omissões geradas por esses sistemas. Essa configuração, resultante da supervalorização da rapidez da produção tradutória, geralmente em detrimento da qualidade, visa a atender a urgência da troca de 
informações, que já não pode mais ser restringida pelo obstáculo da língua na contemporaneidade.

\section{2)O humano auxilia a máquina ou a máquina auxilia o humano?}

A crença na capacidade de a máquina extrair palavras e construções frasais do texto de origem e transpô-las para outra língua, por mais incoerente que seja o texto assim elaborado ao usuário, tem estimulado o desenvolvimento de sistemas comerciais de tradução para uso em computadores pessoais. $\mathrm{O}$ acelerado ritmo atual da comunicação eletrônica favorece a automatização na medida em que exige, em contrapartida, resposta quase instantânea a tudo que é produzido, independentemente das línguas envolvidas. Desde sua criação, a internet tem sido um grande estímulo ao desenvolvimento e à aplicação de sistemas automáticos específicos para tradução de páginas e documentação eletrônicas. A ampla oferta de programas gratuitos de tradução de páginas eletrônicas, por um lado, torna possível que empresas e organizações divulguem informações e serviços a usuários e potenciais clientes que desconheçam a língua original dessas páginas.

Por outro lado, embora o emprego da tradução automática seja indicativo de que, cada vez mais, barreiras linguísticas necessitam ser superadas, há casos de empresas que desconhecem os danos que serviços de baixa qualidade podem causar à sua imagem. De acordo com Hutchins (2005, p.21), algumas empresas fazem uso da automatização para traduzir os materiais textuais em sua páginas eletrônicas a baixo custo e firmam-se na crença de que "a disponibilidade de tradução on-line as absolve de qualquer responsabilidade para com os falantes de línguas estrangeiras usuários de suas páginas eletrônicas".

A mudança no próprio status da informação, muito mais efêmera, e, por conseguinte, da comunicação, muito mais urgente, tem reflexos na prática de tradução, sendo esta vista como uma solução para o problema da diversidade linguística e concebida cada vez menos como um obstáculo. Segundo Hutchins (1997, p.18), a internet "favorece a assimilação rápida e 'superficial' de informações" por usuários que, pelo fato de não possuírem nenhum ou limitado conhecimento de línguas estrangeiras, têm se contentado com a produção de traduções que consideram funcionais para seus objetivos. Sistemas como o Babelfish, o Babylon e o Google Tradutor são exemplos de programas oferecidos 
gratuitamente (muitas vezes, com restrições em algumas funções na versão gratuita) ou para aquisição pela Internet. $\mathrm{Na}$ atualidade, a grande maioria desses sistemas é simplesmente baixada da página de seu desenvolvedor.

Em An Introduction to Machine Translation [Introdução à Tradução Automática], Hutchins e Somers (1992) atribuem aos programas automáticos de baixo custo ou gratuitos na internet o papel exclusivo de produzir "traduções rudimentares" para fins de assimilação geral das informações de um texto, sendo utilizados, com frequência, por especialistas de uma determinada área do conhecimento que necessitam obter informações a partir de documentações redigidas em língua que desconhecem. Como exemplificam os autores, programas como esses seriam muito empregados por cientistas anglo-americanos para leitura de relatórios sobre tecnologia espacial redigidos em russo. Outro contexto de aplicação desses sistemas é encontrado no Japão em que usuários monolíngues empregam a automatização para traduzir conversas on-line com usuários na Europa e nos Estados Unidos. A comunicação é estabelecida por escrito e as mensagens digitadas seriam traduzidas quase instantaneamente, poupando o tempo que seria necessário para elaborar uma carta, traduzi-la, enviá-la e, novamente, traduzir sua resposta. Procurando justificar as limitações da produção do que denominam "tradução automática de baixa qualidade", esses pesquisadores explicam que

[...] é improvável que a produção de um sistema de tradução automática seja muito boa, mas, para leitores técnicos, com conhecimento suficiente de uma área, que sabem o que está acontecendo na ciência de modo geral e que conseguem, até mesmo, adivinhar o assunto de um artigo, ela pode muito bem fornecer material suficiente para, pelo menos, apresentar uma ideia do conteúdo de um texto. (Hutchins; Somers, 1992, p. 157, tradução e grifos nossos)

Nota-se, em Hutchins e Somers (1992), a reiteração do discurso de que a automatização, embora com reconhecidas limitações, é capaz de recuperar o conteúdo do texto de origem, bastando ao usuário desses programas estabelecer a direção da tradução entre os vários pares linguísticos oferecidos pelos diversos sistemas. Esse pensamento também desconsidera o fato de que "a ideia do conteúdo de um texto" não é transmitida automaticamente, mas gerada pela leitura e interpretação do leitor/tradutor do texto. 
Embora a utilização de programas automáticos de tradução continue sendo vista com desconfiança entre a maioria dos tradutores, principalmente aqueles que trabalham com tradução literária, o mesmo parece não ocorrer com grande parte do público usuário da internet, que depende da tradução em sua rotina de trabalho e na comunicação do dia a dia e para o qual "qualquer tradução é melhor do que nenhuma tradução". Esse seria o público disposto a pagar qualquer preço pela rapidez de acesso à informação. Para Hutchins (1997), a urgência de todas as atividades desenvolvidas on-line parece criar um território favorável para utilização de sistemas automáticos de tradução, capazes de atender rapidamente às demandas de seus usuários. Conforme comenta esse autor:

[...] a cultura on-line favorece a assimilação rápida e superficial de informações. Por essa razão, a tradução automática é o futuro óbvio. É agora evidente que o verdadeiro nicho de mercado para a tradução automática está no "espaço cibernético". Embora a produção de baixa qualidade não seja aceitável para os tradutores, ela o é para a maioria do resto da população. Por quanto tempo será aceitável ainda não se sabe; inevitavelmente haverá expectativas de melhoras e o desafio para a comunidade de tradução automática deve ser o desenvolvimento de sistemas projetados especificamente para as necessidades da internet. (Hutchins, 1997, p.118, tradução nossa)

Especialmente em uma era em que a maior parte da comunicação realiza-se em rede e em tempo real, a aplicação da automatização é favorecida por oferecer a promessa de resultados rápidos que requereriam unicamente edição posterior. Para Cronin (2003), o próprio meio eletrônico em que a comunicação se estabelece acaba impondo prazos cada vez menores para o constante processo de revisão e atualização de textos e informações em formato eletrônico, promovendo, em consequência, mudanças no modo como esses materiais são recebidos, lidos e, até, respondidos. A esse respeito, Cronin argumenta que,

[...] se a pressão em uma economia informacional e global é para obter informações o mais rápido possível, então a função de informar os pontos principais torna-se suprema na tradução, uma tendência que pode ser incentivada pela "ausência de peso" das palavras na tela com sua existência evanescente. (Cronin, 2003, p.22, tradução nossa) 
Cronin relaciona as características atuais da composição de materiais escritos em formato digital à adoção da tradução automática por um número progressivo de usuários da internet que, como afirma, estão mais dispostos a aceitar traduções automáticas, mesmo que consideradas de "baixa qualidade", não somente pela gratuidade dos programas oferecidos na rede, mas, principalmente, devido ao "status efêmero do mundo eletrônico" e da produção textual que nele circula.

Apesar da grande oferta de programas de tradução on-line, a aplicação da automatização no contexto comunicativo e digital contemporâneo não constituiria, segundo Hutchins (2001), uma influência negativa para a demanda e a contratação de tradutores humanos. Ao contrário, o desenvolvimento e a aplicação desses sistemas estariam criando novas oportunidades de atuação para esses profissionais, pois, como argumenta, na medida em que a máquina os mune de recursos para traduzir e atualizar documentações extensas e repetitivas, como manuais técnicos e informações em bancos de dados, o tempo de trabalho humano também seria reduzido, possibilitando a dedicação a novos trabalhos.

Por outro lado, o crescente emprego da automatização para atender à demanda de "disseminação" designada por Hutchins tem delineado um novo perfil para o tradutor contemporâneo, que passa a ser contratado basicamente como um encarregado de revisar a produção automática para publicação. A revisão, basicamente entendida como uma etapa de trabalho que se segue ao de tradução, passa a ter uma característica peculiar em textos traduzidos de forma automática. O tradutor encarrega-se de avaliar e adequar um trabalho que tem por vantagem a rapidez de conclusão e, supostamente, a precisão e padronização terminológica. A supervalorização desses atributos desconsidera o fato de um texto considerado "técnico", como manuais, não ser constituído apenas por termos especializados (os quais são armazenados na memória do programa e dela recuperados com rapidez imbatível), mas, em uma frequência muito maior, por palavras de uso corrente, consideradas não técnicas. Na construção do sentido, o trabalho de revisão elaborado pelo tradutor envolve necessariamente a tradução dessas ocorrências e sua adequação aos termos traduzidos de forma automática. Denominado "pós-edição", o trabalho do tradutor é, em mais esse segmento, desvalorizado.

Uma situação que evidencia o emprego de tradutores especificamente para a tarefa de revisão da tradução automática de textos técnicos é constatada em empresas transnacionais, como a fabricante de máquinas e equipamentos para construção Caterpillar. De acordo com um estudo de caso elaborado por Lockwood (2000), essa empresa foi a 
pioneira na implantação de regras de controle de redação de seus textos de origem (manuais) para aplicação de automatização na tradução desse material para as diversas línguas dos países para os quais seus produtos são exportados. Conforme Lockwood (2000, p.188), mais da metade da produção de equipamentos para construção da Caterpillar é voltada a países emergentes, onde a empresa opera por meio de representantes e distribuidores, por isso, "fornecer informações sobre um produto nas línguas locais é uma questão estratégica para a Caterpillar". Os esforços de produção no estágio de pré-edição (ou redação) dos textos de origem concentram-se em reduzir o tempo e os custos de tradução durante a fase de pós-edição, após aplicação da tradução automática.

Na União Europeia, um dos mais antigos e maiores usuários da tradução automática, também se constata o emprego de tradutores para pós-edição de traduções. O sistema mais utilizado, denominado Systran, é empregado para uma produção peculiar: produzir as primeiras versões (ou pré-traduções) de documentos que serão traduzidos para as várias línguas dos países membros. Para tornar possível a aplicação da automatização, grande parte dos documentos produzidos são digitalizados e vários dicionários bilíngues, compilados. Em 2000, Brace publicou seu trabalho sobre a aplicação de sistemas automáticos na União Europeia e constatou que, naquela época, o Systran contava com "mais de quatro milhões de entradas distribuídas em 16 pares linguísticos" (Brace, 2000, p.222).

Brace (2000, p.222) constatou também em seu estudo que a maior parte desses usuários do Systran não seria composta por tradutores, mas funcionários dos vários departamentos administrativos da que empregam esse programa para obter uma primeira tradução, ainda que limitada, de um documento. A tradução automática seria usada também para orientar a produção de minutas de documentos, posteriormente encaminhados aos tradutores do Serviço de Tradução da União Europeia, que reúne mais de 1.500 profissionais. Conforme divulgado na pesquisa que o referido autor conduziu com esses tradutores, a maior parte deles também utiliza o Systran, porém, o fazem exclusivamente como "recurso terminológico" e para preservar a formatação dos documentos traduzidos.

Pode-se inferir, com base no que constatam Lockwood (2000) e Brace (2000), que a aplicação da automatização acelera a produção da tradução por possibilitar a comparação e a recuperação de termos técnicos e, nos casos de autoria controlada do texto de origem, de frases e expressões recorrentes. Por outro lado, não fica nítido o limite que separa o trabalho de tradução automática e daquele de pós-edição humana, considerado somente um 
estágio de adequação e revisão. Embora a automatização da tradução acelere a produção do texto final, o sentido poderá ser construído somente a partir da revisão do tradutor, que confere sentido ao texto de acordo com sua interpretação.

A utilização da tradução automática, ainda que para produção de versões não definitivas, gera a ilusão de ser possível alcançar uma maior neutralidade no texto traduzido. Essa percepção é criada juntamente com todo o projeto de tradução automática, fundamentado na ilusão de possibilidade de transferência ou conversão entre diferentes línguas. Por esse ângulo, assume-se uma noção muito superficial e artificial de língua, na qual cada sentença admite uma só possibilidade de interpretação.

Fundamentadas nessa concepção de língua, muitas empresas transnacionais, que produzem grande volume de documentação e de manuais para produtos de exportação, adotam um "uso controlado" da língua na produção do texto original a fim de alcançar a maior coerência possível com o mínimo de emprego de revisão humana. Conforme exemplifica Hutchins (1999), a multinacional Xerox orienta os autores técnicos responsáveis pela elaboração dos manuais que componham desses documentos no que se denomina "inglês customizado multinacional", que faz uso de termos e construções frasais específicas a fim de evitar ambiguidades e apresentar maior qualidade e rapidez na produção de textos nas mais diversas línguas. Essa seria uma estratégia também para reduzir o tempo empregado pela revisão humana, a cargo do tradutor, que exerce, cada vez mais no âmbito da tradução automática, uma função suplementar à da máquina.

\section{Considerações finais}

A automatização da tradução pode gerar problemas bem diferentes daqueles geralmente apresentados em traduções humanas e, embora se acredite que a ela possa agilizar o trabalho do tradutor, é inevitável que este tenha que lidar com um texto que não foi traduzido por um cérebro humano, o que exige uma abordagem específica para tratar de erros e inadequações. Nesse cenário, fica mais difícil para o tradutor manter o olhar crítico em relação ao texto produzido pela máquina, sendo necessário mais tempo para harmonizar o trabalho mecânico ao humano na produção de um texto final coerente. Ao revisar a produção da máquina, o tradutor realiza escolhas e confere sentido a um texto de acordo com a interpretação que constrói a partir de uma pré-tradução automática e levando em conta a imagem formada do público-alvo de seu trabalho. 
De maneira geral, não se pode ignorar ou negar que as tecnologias que integram o trabalho do tradutor, em forma de ferramentas de auxílio à tradução ou de programas de tradução automática, têm muito a oferecer em termos de aumento de eficiência de produção. Por outro lado, a velocidade com que esses programas estão sendo adotados e o frequente requisito para que os profissionais que desejem se tornar competitivos dominem os recursos desses sistemas, de certa forma, põem em segundo plano a reflexão sobre as consequências da automatização da tradução, seja parcial ou não.

Neste trabalho, procurei chamar a atenção para o fato de que a aplicação atual de programas automáticos de tradução ocasiona alterações já na composição do texto de origem. O emprego de estratégias de controle terminológico e fraseológico, privilegiando construções gramaticais consideradas simples e que dispensam recursos como anáforas e elipses, por exemplo, é uma etapa fundamental para que a automatização produza resultados satisfatórios. Textos assim compostos teriam mais chances de produzirem traduções automáticas parciais que exigiriam menor intervenção pelo tradutor na fase de pós-edição.

Se, em princípio, havia um temor ingênuo de que a automatização um dia resultaria na substituição do tradutor, hoje, o tradutor é visto como imprescindível em projetos sérios que envolvam programas automáticos para produção de grandes volumes de textos. Entretanto, é essencial que se considere os limites da coexistência entre tradutor e máquina, especialmente quando se trata de assumir a responsabilidade sobre a produção do novo significado que o texto traduzido passará a ter.

\section{Referências bibliográficas}

BRACE, Colin. "Language automation at the European Commission". In: Sprung, Robert C. (Ed.). Translating into Success: cutting-edge strategies for going multilingual in a global age. v. 6, ATA Scholarly Monograph Series, 2000. pp. 119-224.

CRONIN, Michael. Translation and globalization. London: Routledge, 2003. 
CURADO, José Manuel. O mito da tradução automática. Revista Electrónica Crítica: Central de Filosofia e Cultura, 9 set 2000. Disponível em: <http://www.terravista.pt/nazare/1339/fil_tradaut.html>. Acesso em 10 mar. 2013.

HUTCHINS, John. Translation Technology and the Translator. Proceedings of the Eleventh Conference of the Institute of Translation and Interpreting, Londres, mai. 1997. Disponível em: <http://ourworld.compuserve.com/homepages.WJHutchins>. Acesso em 10 mai. 2013.

. The development and use of machine translation systems and computer-based translation tools. Proceedings of the International Symposium on Computer Language Information Processing. Pequim, jun. 1999. Disponível em: <http://ourworld.compuserve.com/homepages.WJHutchins>. Acesso em 10 mai. 2013.

Machine translation and human translation: in competition or in complementation? International Journal of Translation, n. 13 (1-2), p. 5-20, Jan./Dec. 2001.

Current commercial machine translation systems and computer-based translation tools: system types and their uses. International Journal of Translation. v. 17, n. 1-2, p. 538, Jan./Dec. 2005.

Machine translation: a concise history. 2007. Disponível em: <http://www.hutchinsweb.me.uk/CUHK-2006.pdf>. Acesso em: 15 ago. 2012.

HUTCHINS, William John; SOMERS, Harold L. An introduction to machine translation. London: Academic Press Limited, 1992. 
KAY, Martin. The proper place of men and machines in language translation. Machine Translation. n.12 (1-2), p. 3-23, 1997.

LOCKWOOD, Rose. "Machine translation and controlled authoring at Caterpillar". In: Sprung, Robert C. (Ed.). Translating into Success: cutting-edge strategies for going multilingual in a global age. v. 6, ATA Scholarly Monograph Series, 2000. p. 187-202.

MARTINS, Ronaldo Teixeira. Tradução automática e estudos da tradução: um conflito paradigmático. In: I TIL - Workshop em Tecnologia da Informação e da Linguagem Humana. São Carlos, SP: 12 out 2003. 